\title{
SACK, M.
}

\section{Von der Neuropathologie zur Phänomenologie. Alfred Prinz Auersperg und die Geschichte der Heidelberger Schule}

Königshausen \& Neumann, Würzburg, 2005. 192 págs.

\section{Fernando Lolas Stepke ${ }^{1}$}

La obra del príncipe Alfred von Auersperg merece recapitulación como una forma de abordar los fenómenos perceptuales, el dolor y la biología en general, y sugiere perspectivas para las consideraciones éticas. No fueron éstas preeminente énfasis en sus publicaciones; precisamente en la dilucidación a partir de lo sugerido y no expresado radica su interés.

Alfred Auersperg nació cerca de Salzburgo, en Austria, en 1899, y murió en Hamburgo, Alemania, en 1968. Tras estudios de la filosofía y la jurisprudencia, se recibió de médico y trabajó en el área de la neuropatología y la neurología clínica. Su vínculo con Viktor von Weizsäcker y las aportaciones que realizó a la teoría del Gestaltkreis (la íntima y complementaria relación entre percibir y actuar) merecieron que sus aportes fueran reconocidos como parte de la llamada Escuela de Heidelberg, movimiento de la medicina antropológica que hizo de la "reintroducción del sujeto en la biología y la medicina" un ideal metódico y un énfasis programático.

Después de estar en el frente durante la Primera Guerra Mundial y de ser parte del esfuerzo bélico del Tercer Reich en la Segunda (como miembro de las SS), el príncipe emigró a América Latina, Brasil primero y luego a Chile, país en el que fundó la cátedra de psiquiatría de la Universidad de Concepción, la cual dirigió hasta su fallecimiento. En esta última etapa de su trabajo se interesó por el alcoholismo y sus psicosis y continuó sus reflexiones sobre temas tan diversos como la motricidad, el dolor y la percepción sensorial. Durante sus años chilenos nunca dejó de volver a Alemania, especialmente a Heidelberg, y cultivó la amistad con sus amigos.

Su producción escrita, sin ser abrumadora, es muy extensa y variada. De difícil lectura, muestra la impronta de la lectura del Goethe naturalista y científico y una aproximación al trabajo experimental que él mismo calificó alguna vez de "diletante" y de "amateur", indicando que el experimento tiene tanto valor metódico como heurístico y no debe ser tomado con rigidez paralizante.

Entre los principales trabajos de Auersperg deben contarse aquellos relacionados con la percepción (Wahrnehmung, en alemán), a partir de los cuales desarrolló el concepto de "Prolepsis". Con él alude a una suerte de anticipación de lo percibido a partir de los actos que se realizarán. La percepción no es algo pasivo y receptivo sino un rendimiento activo (con carácter de subjeto) que realizan los organismos, especialmente los seres humanos. Que los datos psicofísicos coincidan con estas dimensiones subjetivas es asunto de lo que llamó "Coincidentialkorrespondenz", término preferible a "Coincidentialparallelismus" que usó al comienzo. A la Prolepsis se agrega la Analepsis, de modo que hay una determinación anticipatoria y una retroalimentación correctiva de los actos perceptuales. Estas ideas recuerdan, por cierto, las nociones de retroalimentación de la cibernética y el principio de reaferencia de Erich von Holst, con los cuales tiene algunas diferencias. Las principales, demás está decirlo, radican en la negación de la mecanicidad de los sucesos, el carácter "subjetual" del acto perceptivo, que lo equipara a algo creativo, en consonancia con la idea de reintroducir el sujeto en la biología, el dogma de la Escuela de Heidelberg.

En muchos sentidos, como escribí en una contribución al libro Leibliche Bedingungen und personale

${ }^{1}$ Director "Acta Bioethica". Centro Interdisciplinario de Estudios en Bioética, Universidad de Chile, Chile Correspondencia: flolas@uchile.cl 
Entfaltung der Wahrnehmung, editado por Therese zu Oettingen-Spielberg y Hermann Lang en 1994 (basado en un simposio de 1989), estas aproximaciones permiten pensar en algo como la fenomenología de la percepción y se asemejan mucho a la tradicional postura hermenéutica que permanentemente confronta lo percibido con lo prejuiciado y va corrigiendo la interpretación de los textos en constante enfrentamiento con ellos. Una percepción hermenéutica es una percepción "comprensiva”, "animada", "activa”, que se aleja de la estructuración en arcos reflejos que fue de estilo en la neurofisiología mecanicista a la que Auersperg, siguiendo a Weizsäcker, siempre se opuso.

Más que diferencias de interpretación de datos, se trata de una diferencia en la constitución del objeto de estudio y en la forma de configurar el acceso a la realidad. Pues ésta, como decía Merleau-Ponty, no es causa de la percepción sino su resultado o consecuencia. Toda realidad, en tanto que Umwelt, es construcción vital, desarrollada en y por "intereses" del sujeto actuante. Esta noción de Inter-Esse, lo que está "entre los seres", es central para el desarrollo de la idea de Begegnung, encuentro, que es construcción metafórica para designar tanto la relación con la naturaleza inanimada como con otros seres vivos, y con otras personas. De allí derivan interesantes ampliaciones a la psicoterapia, el acompañamiento, la medicina como ayuda en general, disquisiciones sobre la amistad y el amor y, por cierto, la imbricación entre poesía y ciencia, ambas formas complementarias de crear mundos compartidos.

En esta perspectiva se pueden derivar muchas consecuencias para una fundamentación de las percepciones morales y para la elaboración lingüística de sus fundamentaciones, que conocemos como ética. En su obra Auersperg bautizó como "PHysiogenese" una postura que va más allá de lo somático (fisiológico) y lo anímico (psicológico), recurriendo a la noción griega de "Physis", como Naturaleza, y más precisamente, como Naturaleza que crece, se desarrolla y vive. Aunque esta connotación se pierde, por ejemplo, en la denominación de Fisiología para una ciencia de las funciones orgánicas, al rescatarla se impone una concepción de los movimientos vitales que perciben, comprenden e interpretan, configurando un substrato hermenéutico para la experiencia moral y la fundamentación ética.

No estará de más que abordemos la posibilidad de hablar de una "Fisio-Ética" para designar esta perspectiva que se avizora, término más inclusivo tal vez que el de Bio-Ética, que tantas triviales interpretaciones provoca. Si tan solamente fuera por esta sugerencia de denominación, ya la obra de Auersperg merece una relectura. 